\title{
QUEM IRÁ EMPURRAR MINHA CADEIRA DE RODAS? A ESCOLHA DO CUIDADOR FAMILIAR DO IDOSO*
}

\author{
WHO WILL PUSH MY WHEELCHAIR? CHOOSING A FAMILY ELDERCARE PROVIDER*
}

\section{QUIÉN IRÁ EMPUJAR MI SILLA DE RUEDAS? LA ELECCIÓN DEL CUIDADOR FAMILIAR DEL ANCIANO*}

\section{Sofia Cristina lost Pavarini ${ }^{1}$, Fernanda Lopes Tonon ${ }^{2}$, Jeniffer Marcela Carlos Silva ${ }^{3}$, Marisa Zazzetta de Mendiondo $^{4}$, Elizabeth Joan Barham ${ }^{5}$, Carmen Lúcia Alves Filizola ${ }^{6}$}

RESUMO: As relações afetivas e pessoais ao longo da vida podem determinar as relações familiares no processo do envelhecer humano. Este trabalho teve por objetivo avaliar a funcionalidade familiar de idosos pertencentes a um movimento de alfabetização de adultos e identificar quem escolheriam para cuidar deles na velhice. Trata-se de um estudo descritivo e transversal, baseado nos pressupostos do método quantitativo e qualitativo de investigação. Para a avaliação da funcionalidade familiar utilizou-se o Apgar de Família proposto por SMILKSTEIN (1978) e os dados foram analisados estatisticamente segundo medidas de freqüência. Foram avaliados 93 idosos. Para a compreensão da escolha do cuidador foram realizadas entrevistas em profundidade com 9 idosos, sendo três de cada categoria do Apgar. As entrevistas foram analisadas, segundo o Modelo de Análise de Conteúdo, categoria Análise Temática proposta por BARDIN (1977).Todos os cuidados éticos que regem pesquisas com seres humanos foram respeitados. Os resultados do Apgar de família mostram que 81 idosos apresentaram boa funcionalidade familiar, 8 moderada disfunção e 4 elevada disfunção familiar. Os resultados das entrevistas mostram que, nas três categorias do Apgar, a escolha do cuidador foi a mesma no que diz respeito ao gênero (mulher), ao grau de parentesco (filha), à composição familiar (multigeracional), à história de vida e ao relacionamento. "Quem irá empurrar minha cadeira de rodas" é uma escolha determinada por valores sociais e culturais e pela história de vida de cada um. É multideterminada, multivariada e se processa ao longo da vida.

PALAVRAS-CHAVE: Idoso; Família; Geriatria; Enfermagem; Educação.

ABSTRACT: The emotional ties and personal relationships we form during our lives affect the quality of our family relationships when we grow older. The objective of this study was to evaluate family functioning among elderly people attending adult literacy classes and to identify who they would choose to care for them in their older age. It was a descriptive and transverse study, based on the principles of the quantitative and qualitative research method. To the family functioning assessment, it was used the Family Apgar, proposed by SMILKSTEIN (1978) and data were statistically analyzed in frequency measures. 93 elderly people were evaluated. To the comprehension of caregiver choice it was made in-depth interviews with 9 participants, three of them from each Apgar category. Interviews were analyzed, following the Content Analyze Model, Thematic Analyze Category, proposed by BARDIN (1977). Ethical guidelines for research with human participants were followed. Results obtained with the Family Apgar Scale indicate that 81 participants were from well functioning families, 8 presented moderate family dysfunction and 4 presented high family dysfunction. In-depth interviews were conducted with three participants from each category. In all three groups, the caregiver of choice was the same with respect to: gender (female), family relationship (daughter) and family composition (multigenerational). The definition of "Who will push my wheelchair" is a choice determined by sociocultural values and individual life histories; the choice is a multivariate issue, affected by lifelong processes.

KEY WORDS: Aged; Family; Geriatrics; Nursing; Education.

RESUMEN: A lo largo de la vida, los lazos afectivos y personales determinan las relaciones familiares en el proceso de envejecimiento humano. Este trabajo tuvo como objetivos: evaluar la funcionalidad familiar de

\footnotetext{
* Pesquisa financiada pelo Ministério da Educação, através do Programa de Apoio as Atividades de Extensão- PROEXT; Programa de Bolsa de Iniciação Científica PIBIC/CNPq- USFCar, 2004-2005 e pela Pro Reitoria de Extensão da UFSCar. Enfermeira. Professora Doutora do Departamento de Enfermagem da Universidade Federal de São Carlos. Coordenadora do projeto. Líder do Grupo de Pesquisa Saúde e Envelhecimento do CNPq e Membro do Grupo de Pesquisa Saúde e Família. São Carlos/SP E-mail: sofia@power.ufscar.br

${ }^{2}$ Enfermeira. Bolsista PIBIC-CNPq-UFSCar. 2004-2005. São

Carlos/SP E-mail: ferlopes81@yahoo.com.br

${ }^{3}$ Enfermeira. Bolsista da PROEX-UFSCar. 2004-2005. São Carlos/SP E-mail: marcela jeni@yahoo.com.br

4 Assistente Social. Doutora em Serviço Social pela Pontifícia Universidade Católica do Rio Grande do Sul, Doutorado-Sanduíche com Gesamthochschule Kassel-Ghk.em Kassel-Alemanha, Especialista em Gerontologia Social pela PUCRS. Pesquisadora do Grupo de Pesquisa Saúde e Envelhecimento. Vice-coordenadora do projeto. São Carlos/SP E-mail: marisam@power.ufscar.br

${ }^{5}$ Psicóloga. Professora Doutora do Departamento de Psicologia da Universidade Federal de São Carlos. Vice-líder do Grupo de Pesquisa Saúde e Envelhecimento. Membro da equipe coordenadora do projeto. São Carlos/SP E-mail: lisa@power.ufscar.br

6 Enfermeira. Professora Doutora do Departamento de Enfermagem da Universidade Federal de São Carlos. Membro do Grupo de Pesquisa Saúde e Família. São Carlos/SP E-mail: filizola@power.ufscar.br
} 
los ancianos pertenecientes a un movimiento de alfabetización de adultos e identificar a quién ellos elegirían para cuidarlos en la vejez. Tratase de un estudio descriptivo y transversal, con base en los presupuestos del método quantitativo y qualitativo de investigación. Para evaluar la funcionalidad familiar se utilizó el Apgar de Familia propuesto por SMILKSTEIN (1978) y los datos fueron analisados estadisticamente según medidas de frecuencia. Fueron evaluados 93 sujetos. Para la comprensión de la elección del cuidador fueron realizadas entrevistas en profundidad con 9 ancianos, siendo 3 de cada categoria del Apgar. Las entrevistas fueron analisadas según el modelo de análisis de contenido, categoria Análise Temática propuesta por BARDIN (1977). Fueron respetados todos los cuidados éticos que rigen investigaciones con seres humanos. De

\section{INTRODUÇÃO}

A família tem sofrido mudanças sociais ligadas à modernização, dentre elas a maior participação da mulher no mercado de trabalho, a redução do número de componentes, o surgimento de novos papéis de gênero e a maior longevidade de seus membros. Essa maior longevidade tem possibilitado uma convivência familiar intergeracional mais prolongada, permitindo que os indivíduos passem mais tempo de vida nas condições de avós, pais, filhos e netos, e, ainda, apresentem a superposição desses papéis (AQUINO \& CABRAL, 2002).

Dentro do contexto familiar existem relações afetivas e pessoais que marcam presença na construção da história de cada um de seus membros. Nesse sentido, a qualidade dessas relações familiares encontra-se associada à qualidade do cuidado (MENDES, 1998). Um dos fatores significativos de equilíbrio e bem-estar daqueles que envelhecem é a relação de afeto que ocorre no ambiente familiar. O vínculo emocional entre o idoso e seu cuidador é importante para que se construa uma relação de intimidade, e os laços afetivos envolvidos podem favorecer uma maior confiança (PAVARINI et al, 2003; ASSIS, 1998). A qualidade do relacionamento torna-se um aspecto fundamental em que, na situação de cuidar do cônjuge ou dos pais, entram em cena questões afetivas arraigadas nas relações familiares anteriores (NERI \& CARVALHO, 2002).

Quando há a necessidade de um cuidador, cada família enfrenta a situação de acordo com a sua estrutura e com a relação estabelecida com o idoso no decorrer dos anos. O agravo da saúde e a conseqüente necessidade de um cuidador, geralmente não são desvinculados da história de vida do indivíduo (TEIXEIRA, 1998).

O aparecimento da dependência no idoso e a conseqüente necessidade de um cuidador provocam uma reestruturação familiar e uma redefinição de acuerdo con el Apgar de familia, 81 ancianos presentaron funcionalidad familiar buena, 8 disfunción moderada y 4 disfunción familiar elevada. Fueron seleccionados tres ancianos de cada categoría para entrevista en profundidad. Para las tres categorías del Apgar fueron comunes: género (mujer), grado de parentesco (hija), composición familiar (multigeneracional), historia de vida y relaciones sociales."Quién irá empujar mi silla de ruedas" es una elección determinada por valores sociales y culturales y por la historia de vida de cada uno. Es una elección multideterminada, multivariada y que se procesa a lo largo de la vida.

PALABRAS CLAVE: Anciano; Familia; Geriatría; Enfermería; Educación.

papéis, o que pode ocasionar, por exemplo, alterações na rotina e na dinâmica familiar (VILAÇA et al, 2005; KARSCH, 2003; ALVAREZ, 2001; MARCON et al, 1998). O processo de adaptação a essa nova realidade pode, por um lado, não se tornar complicado quando há uma boa relação entre cuidador familiar e idoso dependente, podendo ocorrer um maior grau de intimidade, de confiança e de respeito. Por outro, grandes dificuldades podem ser geradas quando o histórico familiar é construído a partir de crises e conflitos, tornando o cuidado inadequado e penoso para o cuidador.

APGAR DE FAMÍLIA: UM INSTRUMENTO PARA AVALIAÇÃO DO FUNCIONAMENTO FAMILIAR

O Apgar de Família ou Family Apgar, desenvolvido por Smilkstein em 1978 é um instrumento composto por cinco questões que permitem a mensuração da satisfação dos membros da família em relação a cinco componentes considerados básicos na unidade e funcionalidade de qualquer família: adaptação, companheirismo, desenvolvimento, afetividade e capacidade resolutiva (DUARTE, 2001. O acrônimo APGAR, proveniente da língua inglesa, deriva de Adaptation (Adaptação), Partnership (Companheirismo), Growth (Desenvolvimento), Affection (Afetividade) e Resolve (Capacidade resolutiva).

1- Adaptação - relacionada aos recursos familiares oferecidos quando se faz necessária uma assistência;

2- Companheirismo - compreende a reciprocidade nas comunicações familiares e na solução de problemas;

3- Desenvolvimento - associado à liberdade, disponibilidade da família para mudanças de papéis e para alcance de maturidade ou desenvolvimento emocional;

4- Afetividade - relacionada à intimidade e às interações emocionais num contexto familiar; 
5- Capacidade Resolutiva - associada à decisão, determinação ou resolutividade existentes em uma unidade familiar.

No Brasil, a tradução e adaptação do instrumento foram realizadas com o objetivo de verificar as propriedades de medida do Family Apgar quando aplicados a idosos independentes, dependentes e seus cuidadores (DUARTE, 2001). Os resultados obtidos com a aplicação do Apgar são convertidos em escores partindo de uma escala de respostas com cinco opções para cada um dos componentes a serem avaliados. A indicação da resposta "Sempre" corresponde ao escore $=4$, Quase sempre $=3$, Algumas Vezes $=2$, Raramente $=$ 1 e Nunca $=0$. A somatória dos valores obtidos representam o escore que sugere a qualidade da funcionalidade familiar conforme Tabela 1.

Tabela 1 - Classificação do Apgar de Família segundo escore

\begin{tabular}{|c|c|c|}
\hline Escore & $\begin{array}{c}\text { Número de } \\
\text { pontos }\end{array}$ & Classificação \\
\hline $1-8$ & $9(8+1)$ & Elevada disfunção familiar \\
\hline $9-12$ & 4 & $\begin{array}{c}\text { Moderada disfunção } \\
\text { familiar }\end{array}$ \\
\hline $13-20$ & 8 & $\begin{array}{c}\text { Boa funcionalidade } \\
\text { familiar }\end{array}$ \\
\hline
\end{tabular}

Avaliar a funcionalidade familiar de idosos pertencentes a um grupo de alfabetização de adultos e independentes para as atividades de vida diária, parece proporcionar um momento de reflexão sobre as relações familiares no curso da vida. Refletir sobre "quem irá empurrar minha cadeira de rodas" parece instigar a compreensão entre relação familiar e o processo de envelhecimento humano. Assim, este trabalho teve por objetivo avaliar a funcionalidade familiar de idosos participantes de um grupo de alfabetização de um município do interior paulista e identificar, pelos relatos dos idosos, quem escolheriam para cuidar deles na velhice.

\section{METODOLOGIA}

O trabalho baseou-se nos pressupostos do método quantitativo de investigação para avaliação familiar e do método qualitativo para a compreensão da escolha do cuidador. Teve início após a aprovação pelo Comitê de Ética em Pesquisa da instituição onde foi realizado (Protocolo 120/04).

\section{Sujeitos:}

Os sujeitos da pesquisa foram pessoas acima de 60 (sessenta) anos ( $\mathrm{N}=93$ ), de ambos os sexos, participantes de um movimento de alfabetização de adultos (MOVA) de uma cidade do interior do Estado de São Paulo. Participaram das entrevistas em profundidade três idosos de cada escore do Apgar de Família, totalizando nove sujeitos.

\section{Procedimentos:}

A entrevista teve início após a leitura e assinatura do Termo de Consentimento Livre e Esclarecido e seguiu um roteiro previamente estabelecido, contendo dados de caracterização dos sujeitos incluindo questões abertas sobre temas relevantes para o estudo, o Apgar de Família para avaliação do funcionamento familiar e questões sobre a escolha do cuidador.

As entrevistas foram realizadas nos diferentes locais onde ocorriam as aulas de alfabetização, nos vários bairros do município abrangidos pelo programa. Foram previamente agendadas e acordadas com os professores.

Para preservar o anonimato, os nomes dos entrevistados foram substituídos.

\section{RESULTADOS}

\section{CARACTERIZAÇÃO DOS IDOSOS}

A média de idade dos idosos entrevistados foi de 68 anos, sendo que $84(90,3 \%)$ são mulheres e 9 $(9,7 \%)$ homens. Predomina a condição de viuvez (45,2 \% dos entrevistados), seguida pelas condições de casado $(39,8 \%)$, separado $(7,5 \%)$, solteiro $(5,4 \%)$ e outro tipo de união $(2,2 \%)$.

Quanto à composição familiar, foi encontrada uma média de 6,2 filhos, 14,4 netos e 8,6 bisnetos. Os tataranetos aparecem em menor número na composição familiar, sendo dois o máximo encontrado em uma mesma família.

Entre os entrevistados, 78 (83,9\%) idosos informaram que moram com alguém, enquanto que $15(16,1 \%)$ relataram morar sozinhos. Dentre as pessoas que relataram "morar com alguém", a situação familiar encontrada é diversificada, predominando a formação familiar com filhos, podendo o cônjuge estar presente ou não. Os dados obtidos revelaram que 18 moram apenas com o cônjuge, 14 com cônjuge e filhos, 5 com cônjuge, filhos, netos e bisnetos, 50 residem apenas com filhos, netos e bisnetos e 6 relataram outros tipos de formação familiar. A maioria dos idosos (84,6\%) mantêm boas relações com as pessoas com as quais convivem na mesma casa.

Os idosos que relataram morar sozinhos foram questionados em relação às pessoas a quem 
recorrem com maior freqüência. Os dados mostraram que a maioria procura os filhos, seguidos de vizinhos. A maioria $(78,6 \%)$ relatou ainda relacionar-se bem com as pessoas que procuram.

Mais da metade dos idosos $(59,1 \%)$ relatou receber ajuda de alguém da família para algumas atividades, entre as quais destacam-se ajuda para ir ao médico, realizar compras e fazer serviços domésticos. Essas ajudas são provenientes principalmente de filhos e filhas.

Com relação à disponibilidade de auxiliar outras pessoas, a maioria dos idosos relatou ajudar filhos, netos e cônjuge.

Dentre as principais preocupações na velhice, os idosos apontaram a dependência, a doença e a solidão:

"Ficar doente, de cama, dependente de outras pessoas, tenho medo de ser colocada em um asilo e ficar sozinha." (Geralda, 73 anos)
"Ficar em cima de uma cama, doente, sem fazer nada e outros fazendo por mim. Quando eu não tiver agüentando quero que Deus me leve." (Clara, 83 anos)

\section{FUNCIONALIDADE FAMILIAR}

A primeira questão - "Estou satisfeito(a) pois posso recorrer à minha família em busca de ajuda quando alguma coisa está me incomodando ou preocupando" - refere-se ao primeiro componente do Apgar de Família que é a Adaptação. Nessa questão, $8(8,6 \%)$ idosos afirmaram nunca estar satisfeitos ao recorrerem à família em busca de ajuda, $5(5,4 \%)$ responderam que raramente estavam satisfeitos, 10 $(10,4 \%)$ afirmaram algumas vezes estar satisfeitos, 6 $(6,5 \%)$ quase sempre satisfeitos e $64(68,8 \%)$ idosos relataram sempre estar satisfeitos por poderem recorrer à família em busca de ajuda. O Gráfico 1 mostra esses resultados em termos percentuais.

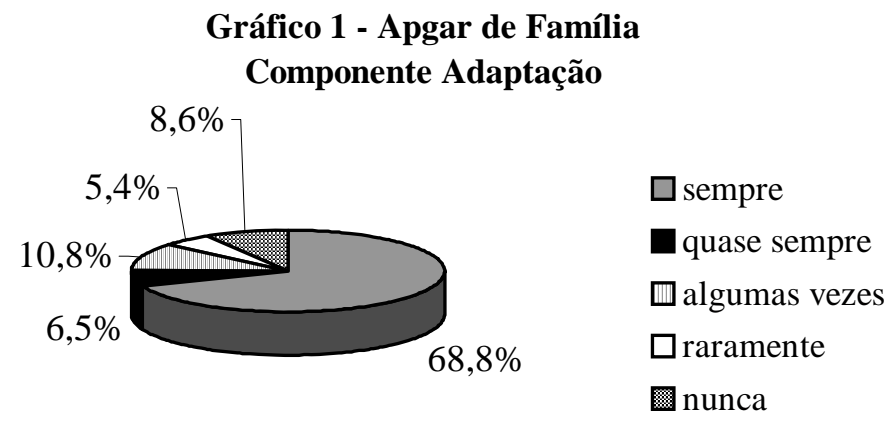

A segunda questão do Apgar de Família "Estou satisfeito(a) com a maneira pela qual minha família e eu conversamos e compartilhamos problemas" - refere-se ao componente Companheirismo. Nesse item, 3 (3,2\%) dos entrevistados relataram nunca estar satisfeitos com a maneira pela qual ocorriam as comunicações familiares e a resolução de problemas, 6 (6,5\%) relataram raramente estar satisfeitos, $10(10,8 \%)$ algumas vezes estavam satisfeitos, 13 (14\%) quase sempre satisfeitos e $61(65,6 \%)$ sempre satisfeitos com a reciprocidade das comunicações familiares e resolução de problemas (Gráfico 2).

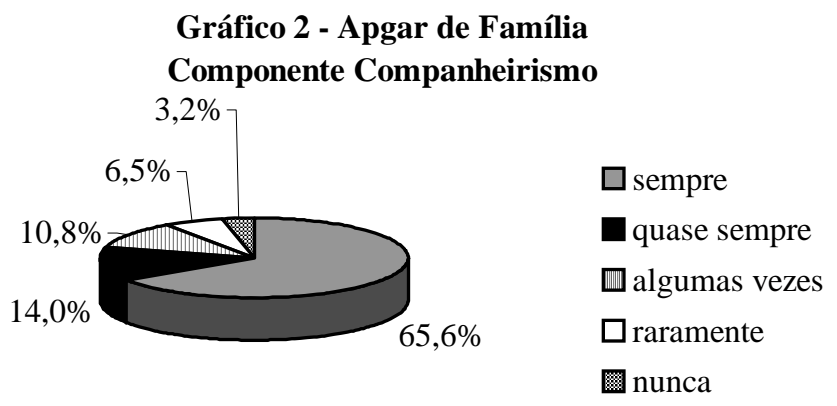

O terceiro componente (Desenvolvimento) "Estou satisfeito(a) com a maneira como minha família aceita e apóia meus desejos de iniciar ou buscar novas atividades e procurar novos caminhos ou direções", foi aquele em que o maior número de idosos (76 ou $81,7 \%$ ) relataram estar sempre satisfeitos. $2 \quad(2,2 \%)$ idosos afirmaram nunca estar satisfeitos com a aceitação da família e o apoio que 
ela oferece, $1(1,1 \%)$ afirmou raramente estar satisfeito, $5 \quad(5,4 \%)$ algumas vezes estavam satisfeitos, $9 \quad(9,7 \%)$ relataram estarem satisfeitos. (Gráfico 3). quase sempre

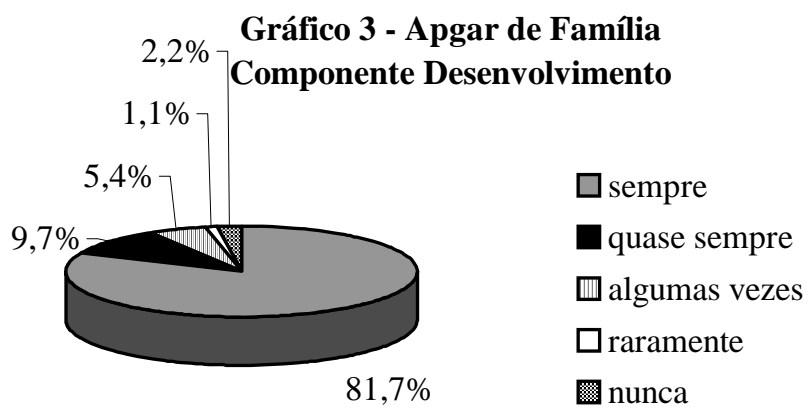

O quarto componente, Afetividade, refere-se à questão "Estou satisfeito(a) com a maneira pela qual minha família demonstra afeição e reage às minhas emoções tais como mágoa, raiva ou amor". Nesse item, os dados representados no Gráfico 4 revelam que $3(3,2 \%)$ entrevistados nunca estavam satisfeitos com as interações emocionais no contexto familiar, 3 $(3,2 \%)$ raramente estavam satisfeitos, $7 \quad(7,5 \%)$ algumas vezes estavam satisfeitos, 7 (7,5\%) afirmaram quase sempre estar satisfeitos e 73 $(78,5 \%)$ idosos relataram sempre estar satisfeitos com a afetividade da família.

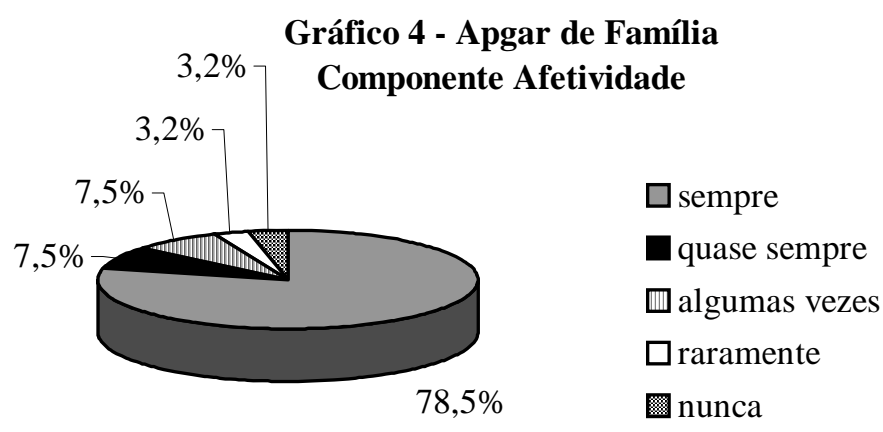

A questão "Estou satisfeito(a) com a maneira pela qual minha família e eu compartilhamos o tempo juntos" está relacionada ao quinto componente, isto é, Capacidade Resolutiva. Nessa questão, 1 (1,1\%) idoso referiu nunca estar satisfeito com a resolutividade existente na dinâmica familiar, 5 (5,4\%) idosos raramente estavam satisfeitos, 9 (9,7\%) algumas vezes estavam satisfeitos, $8(8,6 \%)$ quase sempre estavam satisfeitos e $70(75,3 \%)$ idosos afirmaram sempre estar satisfeitos com a capacidade resolutiva da família. A representação percentual destes dados pode ser vista no Gráfico 5.

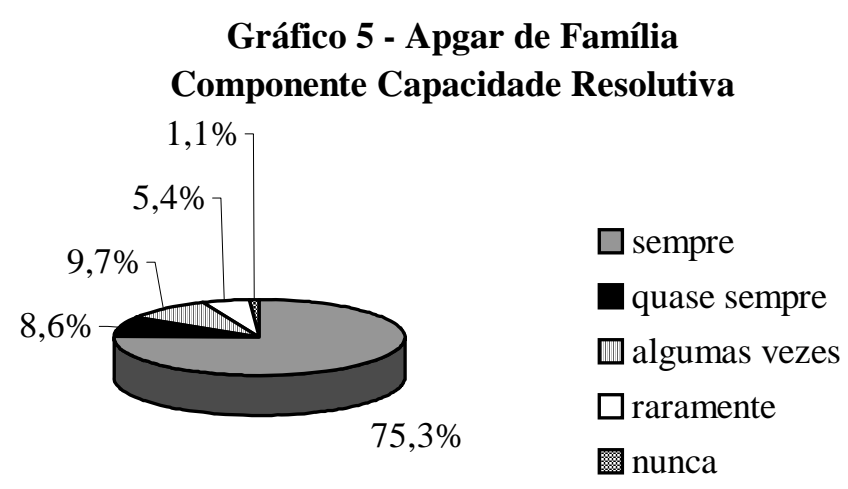

Sendo assim, a categoria " sempre satisfeito" foi acima de $60 \%$ para os cinco componentes avaliados: adaptação (68\%), companheirismo
$(65,6 \%)$ desenvolvimento (81,7\%), afetividade $(78,5 \%)$ e capacidade resolutiva $(75,3 \%)$ e a categoria "nunca satisfeito" foi inferior a $10 \%$ para os 
cinco componentes, sendo que a maior porcentagem foi para o componente adaptação com $8,6 \%$ dos idosos entrevistados terem afirmado " nunca estar satisfeitos ao recorrerem à família em busca de ajuda".

Finalmente, totalizando e agrupando os escores dos entrevistados em relação à funcionalidade familiar, verificou-se que a maioria 81 idosos $(87,1 \%)$ - apresenta boa funcionalidade familiar. Do restante, $8 \quad(8,6 \%)$ apresentaram moderada disfunção familiar e 4 (4,3\%) apresentaram elevada disfunção familiar.

Os resultados de um estudo realizado com 95 famílias de uma comunidade no interior do estado de Falcon, na Venezuela, mostram que $75 \%$ apresentam boa funcionalidade familiar ou leve disfunção familiar (FERRER, 2003). Na Espanha, estudo com 278 pacientes com doença pulmonar obstrutiva crônica, obteve no Apgar de família $79,7 \%$ com boa funcionalidade familiar (VARGAS et al, 2001).

O estudo de DUARTE (2001), comparando o resultado do Apgar em idosos brasileiros independentes, dependentes e seus cuidadores, mostra que este instrumento é capaz de verificar o impacto da dependência na dinâmica familiar. Os valores do APGAR de família foram inferiores nos grupos de idosos dependentes e no grupo dos cuidadores de idosos, mostrando que o funcionamento da família no cumprimento de suas funções enquanto unidade familiar está mais comprometido quando comparados com os valores dos idosos independentes.

Este trabalho buscou avaliar o funcionamento familiar do ponto de vista do idoso independente, participante de um movimento de alfabetização de adultos. Pode haver, no entanto, para os membros de uma mesma família, diferentes percepções sobre o funcionamento familiar. Segundo DUARTE (2001), "uma análise do conjunto pode nos fornecer subsídios para o planejamento de intervenções mais apropriadas de forma a minimizar o impacto da doença ou da condição de dependência sobre o sistema familiar como um todo" (p. 136). Seria desejável então, incluir a avaliação com os demais membros da família dos idosos entrevistados.

Mesmo assim, os resultados permitiram compreender a dinâmica do funcionamento familiar sob a ótica dos idosos nos levando a investigar os fatores que os levariam a optar por alguém para assumir os seus cuidados caso se encontrassem numa situação de dependência.

\section{ESCOLHA DO CUIDADOR FAMILIAR}

Três idosos de cada classificação do Apgar de família, escolhidos aleatoriamente, foram entrevistados tendo a seguinte questão norteadora: "Se o(a) senhor (a) pudesse escolher uma pessoa para cuidar do senhor (a) na velhice caso tivesse necessidade, quem o senhor (a) escolheria? Em seguida, indagava-se ao entrevistado as razões pelas quais ele indicava aquela pessoa.

Os dados foram analisados, segundo o Modelo de Análise de Conteúdo, categoria Análise Temática (BARDIN,1977). O Quadro 1 apresenta as categorias de análise indicando a existência de respostas em cada agrupamento da avaliação familiar. 
Quadro 1 - Variáveis referentes à escolha do cuidador, segundo os idosos entrevistados nas três classificações do Apgar de Família

\author{
Variáveis para a \\ escolha de um cuidador \\ História de vida \\ Gênero \\ Grau de parentesco

História de vida
Gênero
Grau de parentesco
Composição familia
Relacionamento
(afetividade, afinidade,
intimidade)
Proximidade física

Funcionalidade Familiar
Moderada
ção Familiar

$\sqrt{ }$

$\sqrt{ }$

$\sqrt{ }$

$\sqrt{ }$

$\sqrt{ }$

$\sqrt{ }$

$\sqrt{ }$

$\sqrt{ }$

$\sqrt{ }$
Elevada
Disfunção
Familiar
$\sqrt{ }$

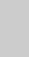

$\sqrt{ }$

\author{
cuidado \\ Experiência em
}

\author{
Formação \\ profissional \\ econômica
}

As variáveis história de vida, gênero, grau de parentesco, composição familiar e relacionamento foram citadas por entrevistados dos três escores. Já as variáveis proximidade física e experiência em cuidado apareceram apenas para aqueles cujo Apgar foi de Boa Funcionalidade Familiar. Fatores como formação profissional e condição socioeconômica estavam presentes no escore de Moderada Disfunção Familiar. Para o escore de Elevada Disfunção Familiar aparece, além da formação profissional, a variável relação de amizade.

Existem estudos que se referem à escolha do cuidador familiar do idoso, porém numa perspectiva em que essa opção já havia sido definida, pois o idoso já se encontrava numa situação de dependência. Nestas pesquisas prevalecem as variáveis gênero, grau de parentesco, proximidade física e proximidade afetiva como determinantes da escolha do cuidador familiar do idoso (CATTANI \& GIRARDON-PERLINI, 2004; KARSCH, 2003; MENDES,1998;). No estudo aqui realizado, mesmo em se tratando de idosos independentes e que não tem necessidade imediata de um cuidador, as variáveis gênero, grau de parentesco e relacionamento (ou proximidade afetiva) também são fatores que exercem influência na escolha do idoso por um cuidador. Outras variáveis presentes neste estudo foram a composição e o histórico familiar, visto que, pelos relatos das entrevistas, a forma como a família está constituída, o número de pessoas que faz parte dela, a história que essa família constrói ao longo dos anos e os laços que se estabelecem nessas relações influenciam consideravelmente na opção dos idosos sujeitos deste estudo.

O conteúdo presente nas categorias criadas ilustra a escolha do cuidador na ótica do idoso.

Gênero - Esta variável aparece para os três escores do Apgar de Família, sendo que a escolha preferencial foi para mulheres. Vários autores consideram uma questão cultural e social no Brasil a predominância de escolha por mulheres para o cuidado. Essa questão está implícita no próprio papel social da mulher, seja como esposa, filha ou nora (CALDAS, 2003; KARSCH, 2003; ALVAREZ, 2001; NERI, 2001; MARCON et al, 1998). Quanto à escolha 
por pessoas do sexo masculino, essa recai quando o cuidado a ser prestado está relacionado ás Atividades Instrumentais da Vida Diária, principalmente em se tratando de atividades relacionadas às finanças. $\mathrm{O}$ cuidador raramente é um homem e os filhos ou genros, quando prestam assistência, o fazem oferecendo ajuda material, cuidando dos interesses econômicos dos idosos e colaborando em tarefas de ajuda instrumental (NERI \& CARVALHO, 2002).

Grau de Parentesco - Conforme os relatos dos entrevistados prevaleceram a escolha pela filha. O grau de parentesco exerce influência decisiva na escolha de quem irá cuidar, visto que pode tornar a relação familiar mais próxima. Estudos mostram que o cônjuge surge como primeira opção de escolha, fruto da obrigação matrimonial e do dever moral estabelecido pela sociedade (CATTANI \& GIRARDON-PERLINI, 2004; KARSCH, 2003; SANTOS, 2003). Porém, neste estudo, a primeira opção foi pela filha, já que cinco das nove entrevistadas eram viúvas, uma era solteira e três casadas. Das casadas, uma já exercia o papel de cuidadora do marido. No Brasil, as filhas assumem tradicionalmente a responsabilidade pelos cuidados. Além da filha, a nora, a neta e a sobrinha também apareceram como alternativas de escolha.

Relacionamento - A afetividade nos relacionamentos, assim como o grau de intimidade e afinidade entre os membros de uma família são fatores levados em consideração frente à decisão de escolher alguém para ser o cuidador. Podemos perceber que os laços existentes entre mãe e filha ou entre avó e neta são significativos para a escolha.

"Aí tem que ser minha filha (...) eu prefiro ela porque nora não é igual a filha. A gente não tem assim tanta liberdade, não sei se ia dar certo não. Com a filha a gente têm mais afinidade." (Nilva, 61 anos)

"Eu só tenho uma que eu conto com ela para me ajudar (...) minha neta, ela eu tenho certeza que se eu precisar ela vem me ajudar. O amor dela por mim é demais. Eu sou vó, pra ela eu sou vó, sou mãe, sou tudo pra ela..." (Conceição, 67 anos)

História de vida - A história de vida possui grande significado na escolha de um cuidador. O fato da filha ser solteira e morar com os pais a torna elegível para o cuidado na maioria dos casos (SANTOS, 2003). Uma filha solteira que mora com os pais, um parente ou amigo próximo que se agrega a família, ou mesmo a falta de um parente próximo podem determinar a escolha do cuidador. Uma das entrevistadas era solteira e, num primeiro momento, teve dificuldade em responder à questão. Por fim, a sua escolha foi pela sobrinha, provavelmente pelo fato de ter morado com a idosa desde pequena e ter sido criada por ela, ressaltando novamente a questão da obrigação filial. Uma outra opção apontada pelos entrevistados foi por uma instituição de longa permanência, resultante do fato de que a idosa "não quer ser mais um problema para a filha" que mora em cidade distante.

Composição Familiar - Uma das entrevistadas relatou que sua opção era restrita uma vez que era viúva e possuía dois filhos.

“... a minha família é pequena, só tenho os dois. Então eu não posso falar que eu não vou querer meus filhos, é só os dois que eu tenho. " (Nilva, 61 anos)

Outra entrevistada não possuía irmãos e filhos, vivendo apenas com seu marido, que precisava dos seus cuidados. Em famílias constituídas apenas pelo casal, a responsabilidade recai normalmente no esposo ou esposa (SANTOS, 2003). No caso dessa idosa, não tendo marido como opção, sua escolha restringiu-se a ponto de não conseguir indicar qualquer pessoa para a função de cuidador.

Em outros casos, a instituição de longa permanência foi apontada também como uma opção:

"Meu caso é melhor ir para um asilo, ficar num asilo. Porque o asilo tem muitas pessoas de idade e eu tenho certeza que lá eu vou ser bem olhada. " (Lourdes, 70 anos)

Proximidade Física - Apesar de ser uma variável muito presente em outros estudos (CATTANI \& GIRARDON-PERLINI, 2004; KARSCH, 2003; MARCON et al, 1998), neste trabalho a proximidade física foi apontada uma única vez. Vale ressaltar que se tratava de um filho que morava numa casa contígua a casa da mãe.

"Eu, para mim escolher não tenho escolha, porque quando eu preciso todos eles ajuda, mas é o que tá mais perto (...) porque é ele que sempre ta aí, minha casa está encostada com a dele." (Zenaide, 78 anos)

Relação de Amizade - As relações de amizade possuem o seu valor, não apenas para estabelecer uma relação de cuidado direto ao idoso, mas principalmente para fazer parte de uma rede de apoio às famílias e ao próprio idoso, auxiliando através de suporte material e/ou emocional (ALVAREZ, 2001).

"Tem uma conhecida minha lá (...) ela sempre fala se eu quiser ela vem ficar comigo." (Beatriz, 74 anos)

Experiência em Cuidado e formação profissional - A condição de determinada pessoa ter sido cuidadora numa outra situação pode levar o idoso ou mesmo a família a acreditar que esteja 
habilitada para tal função (NERI \& CARVALHO, 2002; ALVAREZ, 2001). A escolha baseada neste critério também foi relatada por um dos entrevistados.

\section{CONCLUSÃO}

O Apgar de Família mostrou ser um instrumento importante para avaliar o funcionamento familiar de idosos independentes, participantes de um programa de alfabetização para adultos. Possibilitou um momento importante para pensar as relações familiares e contribuiu para a compreensão dos relatos dos entrevistados sobre a escolha do seu cuidador na velhice.

É importante ressaltar que muitos idosos inicialmente se surpreenderam com as questões. Pensar a situação de dependência antes que ela ocorra parece não ser uma situação presente no cotidiano dos idosos. Mas, sem dúvida, permitiu uma reflexão sobre a dependência na velhice e sobre as relações familiares ao longo da vida.

Os resultados mostram que a maioria dos idosos avaliados apresenta boa funcionalidade familiar. Os motivos que levam a escolha por um cuidador são variados, porém destacam-se, independentemente da funcionalidade familiar, o gênero (mulher), o grau de parentesco (filha), a história de vida, a composição familiar (famílias multigeracionais) e o relacionamento (afetuoso).

Assim, "Quem irá empurrar minha cadeira de rodas" é uma escolha determinada por valores sociais, culturais e pela história de vida de cada um. É, sem dúvida, multideterminada e multivariada, e se processa ao longo da vida.

É fundamental destacar que os fatores encontrados neste estudo são semelhantes àqueles encontrados em pesquisas com idosos dependentes. No entanto, poucos são os estudos que enfatizam a reflexão da dependência na velhice antes que ela ocorra.

Procedimentos que possam estimular uma reflexão sobre o envelhecimento, a dependência na velhice e o cuidado certamente contribuem para a melhoria da qualidade do processo de viver humano.

\section{REFERÊNCIAS BIBLIOGRÁFICAS}

ALVAREZ, A. M. Tendo que cuidar: a vivência do idoso e de sua família cuidadora no processo de cuidar e ser cuidado em contexto domiciliar. 2001. 183 p. Tese (Doutorado) Centro de Ciências da Saúde, Universidade Federal de Santa Catarina, Florianópolis.

AQUINO, F. T. M. de; CABRAL, B. E. S. O idoso e a família. In: FREITAS, E. V. et al (Org.). Tratado de geriatria e gerontologia. Rio de Janeiro: Guanabara Koogan, 2002.

ASSIS, M. O envelhecimento e suas conseqüências In: CALDAS, C. P. (Org.). A saúde do idoso: a arte de cuidar Rio de Janeiro: UERJ, 1998.
BARDIN, L. Análise de Conteúdo. Lisboa, Edições 70, 1977.

CALDAS, C. P. Envelhecimento com dependência: responsabilidades e demandas da família. Cad. Saúde Pública. Rio de Janeiro, v.19, n.3, p.773-81, 2003.

CATTANI, R. B.; GIRARDON-PERLINI, N. M. O. Cuidar do idoso doente no domicílio na voz de cuidadores familiares. Revista Eletrônica de Enfermagem [online], 2004 Disponível em: http://www.fen.ufg.br/revista/revista6 2/idoso.html [Acesso em 05 de set. 2006].

DUARTE, Y. A. O. Família: rede de suporte ou fator estressor. A ótica de idosos e cuidadores familiares. 2001. Tese (Doutorado) Escola de Enfermagem, Universidade de São Paulo, São Paulo.

FERNANDEZ VARGAS, A. M. F. et al. Salud autopercibida, apoyo social y familiar de los pacientes con enfermedad pulmonary obstructive crônica. Medifam. Madrid, [online] 2001. Disponível em: http://wwwscielo.isciii.es/scielo.php?script=sci arttext \&pid=S1131-57682001000900003\&lng=en\&nrm=iso.

[Acesso em 05 de set. 2006].

FERRER, M. Valores y funcionabilidad familiar em habitantes del sector San José Coro-Falcón. Méd. fam. Caracas; v.11, n.2, p.20-27, 2003.

$\mathrm{KARSCH}$, U. M. S. Idosos dependentes: famílias e cuidadores. Cad. Saúde Pública, Rio de Janeiro v.19, n.3, p. 861-866, 2003.

MARCON, S. S.; ANDRADE, O G.; SILVA, D. M. P. Percepção de cuidadores familiares sobre o cuidado no domicílio. Texto Contexto Enf. Florianópolis, v.7, n.2, p.289-307, 1998.

MENDES, P. M. T. Cuidadores: heróis anônimos do cotidiano. In: KARSCH, U.M.S. (Org). Envelhecimento com dependência: revelando cuidadores. São Paulo: Educ, 1998.

NERI, A L. Palavras-chave em gerontologia. Campinas: Alínea, 2001.

NERI, A L.; CARVALHO, V. A L. O bem-estar do cuidador: aspectos psicossociais In: FREITAS, E. V. et al (Org.). Tratado de geriatria e gerontologia. Rio de Janeiro: Guanabara Koogan, 2002.

PAVARINI, S. C. I. et al Identificando fatores que afetam a relação entre idoso e seu cuidador familiar. 2003. Relatório Final (Projeto Universal. CNPq. Processo $n^{\circ}$ 476155/2001-0). Departamento de Enfermagem, Universidade Federal de São Carlos, São Carlos/SP.

SANTOS, S. M. A O cuidador familiar de idosos com demência: um estudo qualitativo em famílias de origem nipo-brasileira e brasileira. 2003. Tese (Doutorado) Faculdade de Educação, Universidade Estadual de Campinas, Campinas.

TEIXEIRA, M. H. Relação interpessoal: cuidadoridoso dependente/cuidador-família. In: CALDAS, C. P. (Org.). A saúde do idoso: a arte de cuidar. Rio de Janeiro: UERJ, 1998.

VILAÇA, C. M. et al O autocuidado de cuidadores informais em domicilio - percepção de acadêmicos de 
PAVARINI, S. C. I.; TONON, F. L.; SILVA, J. M.C.; MENDIONDO, M. Z.; BARHAM, E. J.; FILIZOLA, C. L. A. QUEM IRÁ EMPURRAR MINHA CADEIRA DE RODAS? A ESCOLHA DO CUIDADOR FAMILIAR DO IDOSO. Revista Eletrônica de Enfermagem, v. 08, n. $03, p .326$ - 335, 2006. Disponível em http://www.fen.ufg.br/revista/revista8 3/v8n3a03.htm

enfermagem. Revista Eletrônica de Enfermagem [online], $2005 . \quad$ Disponível em: http://www.fen.ufg.br/revista/revista7 2/relato 02.htm. [Acesso em 25. de set. 2006]

Artigo recebido em 27.11.2006

Aprovado para publicação em 29.12.2006 